\title{
Fluoxetine effect on gestation and fetal development
}

\author{
Ösz Bianca Eugenia, Vari CE, Dogaru Maria \\ University of Medicine ad Pharmacy of Tirgu Mures
}

The prenatal exposure to selective serotonin reuptake inhibitors (SSRIs) is very controversial. There is no conclusive evidence for increased risk of malformations after SSRI use in pregnancy. The aim of the study was to determine how fluoxetine is affecting gestation and fetal development in rats. Twenty sexually mature female Wistar rats weighting between $250-260 \mathrm{~g}$ received $20 \mathrm{mg} / \mathrm{kg}$ body weight fluoxetine from the first day of gestation and during the entire gestation period. The drug was administered by oral route. Healthy, primipareus animals were selected along with 20 female Wistar rats, as control group. Mature males were caged with virgin females for an entire week. Rat's behaviour during gestation, after birth and rats body weight was examined. The number of healthy pups was also noted. The females not giving birth after 21 days to any pup were anesthetized (halothane through gas scavenging apparatus untilled death) and the gravid uterus were dissected out and examined. Compared to the controlled group, in which weight gain was more significant, the animals from the experimental group had a slight increase in body weight. The weight gain normally induced by gestation, is less significant in fluoxetine treated rats due to the increase serotonin levels in the brain. The uteri examination of pregnant rats showed an increase in the number of dead and resorbed rat embryos. Preclinical studies suggest that the inclusion of fluoxetine in pregnancy category $\mathrm{C}$ is justified and the appropriateness of its administration in pregnancy is still an unresolved issue.

Key words: fluoxetine, rat, teratogenicity, death embryos.

Received: 11 May 2014 / Accepted: 14 August 2014

\section{Introduction}

Fluoxetine is the most studied SSRI antidepressant.

SSRI exposure during pregnancy was associated with earlier delivery and consequent lower birth weight [1]. In a prospective study conducted by Merlob P, 2009, between 2000-2007 newborns exposed in utero to SSRIs, had a twofold higher risk of mild nonsyndromic heart defects (ventricular septal defect, bicuspid aortic valve and right superior vena cava to coronary sinus) than unexposed infants [2]. In another prospective study, exposure to SSRIs was not associated with either increased risk for major malformations or higher rates of miscarriage, stillbirth, or prematurity [3].

A meta-analytical review of epidemiological studies suggests that the use of fluoxetine during the first trimester of pregnancy is not associated with significant teratogenic effects in humans [4].

Preclinical studies have revealed fetal growth retardation and skeletal malformations in pregnant mice's after 0.052 , $0.104 \& 0.208 \mathrm{mg} / \mathrm{mouse} /$ day [5].

\section{Material and method}

Twenty sexually mature female Wistar rats weighting between $250-260 \mathrm{~g}$ received $20 \mathrm{mg} / \mathrm{kg}$ body weight fluoxetine from the first day of gestation and during the entire gestation period.The drug was suspended in distilled water and administered by oral route. The animals were obtained from the University of Medicine and Pharmacy Biobase. Healthy, primipareus animals were selected along with 20

Correspondence to: Ösz Bianca Eugenia

E-mail: bianca_eugenia83@yahoo.com female Wistar rats, as control group. Mature males were caged with virgin females for an entire week. To ensure that the medication was administrated from the first day of gestation the mating was made when female rats showed lordosis (the characteristic position adopted by female rats when they are ovulating - copulative behaviour) after exposure to male smell. The control and the experimental groups were kept under the same conditions and they had free access to water and food. Rat'sbehaviour during gestation, after birth and rats body weight was examined. The number of healthy pups was also noted. The females not giving birth after 25 days to any pump were anesthetized (halothane through gas scavenging apparatus untilled death) and the gravid uterus were dissected out and examined. Because in rats fluoxetine has a higher rate of hepatic intrinsic clearance (in vitro) we used a higher than therapeutically employed dose [6].

\section{Results}

In four animalsafter the first week an increase in body weight was seen in fluoxetine treated group then animals lost weight. At the end of the supposed gestation period $(\sim 22$ days) these animals were anesthetized (halothane through gas scavenging apparatus untilled death) and the uterus revealed no gestation. The fluoxetine selectively inhibits serotonin uptake and enhance serotonin levels in brain that inhibits food intake. After multiple doses of fluoxetine a decrease in body weight is expected. In rats, fluoxetine suppress stress-induced eating, suppress carbohydrate consumption selectively, and suppress insulin-induced hyperphagia [7]. 
Rat's weights during gestation aresummarized in Tabel I for the Control group and Tabel II for the Experimental group.

The females not giving birth after 25 days to any pup were anesthetized (halothane through gas scavenging apparatus untilled death) and the gravid uterus were dissected out and examined.

In the control group 15 gestations were obtain with 105 live pups.

In the experimental group from the 16 gestations (126 conceptus), we obtained 73 live pups (58\%), 32 live fetuses $(25 \%)$, but there were also seen 6 early resorbed embryos $(5 \%)$ and 15 death fetuses (12\%). (Tabel III)

In six female rats $(30 \%)$ treated with fluoxetine resorbed embryos were seen. In three cases the uteri examination revealed only resorbtion but in the others there were also live embryos. (Figure $1-\mathrm{B}, \mathrm{C}$ )

In the case of one female rat, after 2 days of vaginal bleeding, caesarean section was done and after external examination of abnormalities of fetuses, fetal internal bleeding and rounded craniofacial morphology were observed. (Figure 1 - D).

\section{Discussion and conclusion}

Compared to the controlled group, in which weight gain was more significant the animals from the experimental group had a slight increase in body weight.

Table I. Control group weight

\begin{tabular}{ccccc}
\hline Crt. Nr. & $\begin{array}{c}\text { Initial } \\
\text { weight }\end{array}$ & $\begin{array}{c}\text { The weight } \\
\text { after 1 week }\end{array}$ & $\begin{array}{c}\text { The weight } \\
\text { after } 2 \text { weeks }\end{array}$ & $\begin{array}{c}\text { The weight } \\
\text { after } 3 \text { weeks }\end{array}$ \\
\hline Average & 267.5 & 280.25 & 293.25 & 306.25 \\
SD & 15.51739 & 18.52985 & 21.78091 & 26.5505 \\
p & & & & $\mathrm{p}=9.321 \times 10-8$ \\
\hline
\end{tabular}

Table II. Experimental group weight

\begin{tabular}{ccccc}
\hline Crt. Nr. & $\begin{array}{c}\text { Initial } \\
\text { weight }\end{array}$ & $\begin{array}{c}\text { The weight } \\
\text { after 1 week }\end{array}$ & $\begin{array}{c}\text { The weight } \\
\text { after 2 weeks }\end{array}$ & $\begin{array}{c}\text { The weight } \\
\text { after } 3 \text { weeks }\end{array}$ \\
\hline Average & 255.75 & 283.25 & 281.25 & 283.75 \\
SD & 4.9404 & 15.2414 & 22.7037 & 24.4343 \\
p & & 0.5793 & 0.0962 & $1.489 \times 10-5$ \\
$\begin{array}{c}\text { pexpvs. } \\
\text { pcontrol }\end{array}$ & & & & $\mathrm{p}<0.01$ \\
\hline
\end{tabular}

Table III. Fluoxetine influence on fetal development compared with control animals.

\begin{tabular}{cccccc}
\hline & Gestations & $\begin{array}{c}\text { Live } \\
\text { pups }\end{array}$ & $\begin{array}{c}\text { Resorbed } \\
\text { embryos }\end{array}$ & $\begin{array}{c}\text { Live } \\
\text { fetuses }\end{array}$ & $\begin{array}{c}\text { Deadfe- } \\
\text { tuses }\end{array}$ \\
\hline $\begin{array}{c}\text { Control group } \\
\text { Experimental } \\
\text { group }\end{array}$ & 15 & 105 & - & - & - \\
\hline
\end{tabular}

Although after the first week of treatment weight gain was not statistically significant between the fluoxetine threated group and the control group $(\mathrm{p}=0.57)$ at the end of the gestation period the difference between the two groups was statistically significant $(\mathrm{p}<0.05)$. This can be explained by serotonin increased levels in the brain in fluoxetine treated animals. These results are comparable to those seen after fluoxetine prenatal exposure in rats and rabbits. Studies made on rats and rabbits did not revealed any reproductive toxicity at doses that were maternally toxic but there was a depression of maternal weight gain and food consumption. [8]

Clinical [9] and preclinical studieshave demonstrated that excess serotonergic stimulation of medial hypothalamus is leading to anorexia and decreases food intake.

On the other hand, because fluoxetine is affecting intrauterine fetal development, the number of uteri implantation and embryos is smaller compared with control group and this can also explain the reduction in weight gain.

The fetal internal bleeding seen in our study, because was singular, can be correlatedwith a prolonged labour, which affected the fetuses although a study made on rats suggests that fluoxetine might cause adverse vascular effects. In the present study fluoxetine exposed offspring showed a statistically higher frequency of skin hematomas when compared to controls [10].
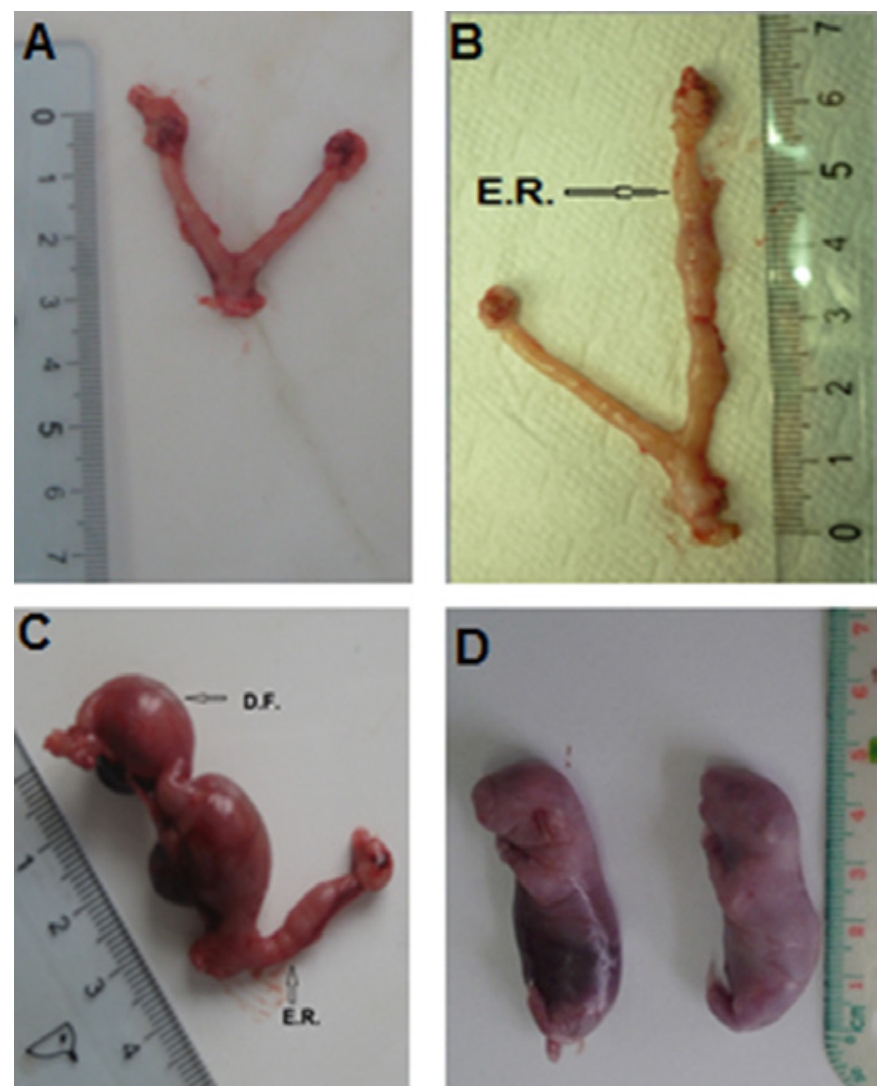

Figure 1 - A. Normal uterus (control animal group), B. Early resorbed embryos (E.R.), C. Death fetuses (D.F) and early resorbed embryos (R.E). D. Death fetuses, fetal internal bleeding, rounded craniofacial morphology (fluoxetine treated animals) 
There are no human studies or case reports to suggest that fluoxetine is teratogenic.

The incidence of congenital malformation in neonates exposed to fluoxetine during the first trimester (128 pregnant women) was comparable to those exposed to either nonteratogens or tricyclic antidepressants. However women treated with fluoxetine had a tendency for increased risk for miscarriage when compared with women exposed to nonteratogens [11].

A multicentre, prospective, controlled studywhich evaluated the rate of major congenital anomalies after firsttrimester gestational exposure to fluoxetine (314 fluoxetine first-trimester exposed pregnancies) or nonteratogens (1467 controls) suggests a possible association between cardiovascular anomalies and first-trimester exposure to fluoxetine [12].

Preclinical studies suggest that the inclusion of fluoxetine in pregnancy category $\mathrm{C}$ is justified and the appropriateness of its administration in pregnancy is still an unresolved issue. Therefore, for complete understanding fluoxetine impact on fetal development long-term investigations are required not only in animals but in humans also.

\section{References}

1. Simon GE, Cunningham ML, Davis RL - Outcomes of prenatal antidepressant exposure. Am J Psychiatry. 2002;159(12):2055-2061.

2. Merlob P, Birk E, Sirota L, Linder N, Berant M, Stahl B, Klinger G - Are selective serotonin reuptake inhibitors cardiac teratogens?
Echocardiographic screening of newborns with persistent heart murmur. Birth Defects. Res A Clin Mol Teratol. 2009;85(10):837-841.

3. Kulin NA, Pastuszak A, Sage SR, Schick-Boschetto B, Spivey G, Feldkamp M, Ormond K, Matsui D, Stein-Schechman AK, Cook L, Brochu J, Rieder M, Koren G - Pregnancy outcome following maternal use of the new selective serotonin reuptake inhibitors: a prospective controlled multicenter study. JAMA. 1998;279(8):609-610.

4. Addis A, Koren G - Safety of fluoxetine during the first trimester of pregnancy: a meta-analytical review of epidemiological studies. Psychol Med. 2000;30:89-94.

5. Ali MO, Sharf-El Deen UA, El Menshawy OM, Bakry SA - Fluoxetine Hcl Induced Intrauterine Foetal Growth Retardation And Skeletal Malformation In Pregnant Mice, The Egyptian Journal of Hospital Medicine, 2002;6:6379.

6. Stevens JC, Wrighton SA - Interaction of the enantiomers of fluoxetine and norfluoxetine with human liver cytochromes P450. J Pharmacol Exp Ther. 1993;266:964-971.

7. Yen T, Fuller RW - Preclinical pharmacology of fluoxetine, a serotonergic drug for weight loss. Am J ClinNutr. 1992;55(1 Suppl):177S-180S.

8. Byrd RA, Markham JK - Developmental toxicology studies of fluoxetine hydrochloride administered orally to rats and rabbits. Fund Appl Toxicol. 1994;22(4):511-518.

9. Stevens JC, Wrighton SA - Interaction of the enantiomers of fluoxetine and norfluoxetine with human liver cytochromes P450. J Pharmacol Exp Ther. 1993;266:964-971.

10. Stanford MS, Patton JH - In utero exposure to fluoxetine $\mathrm{HCl}$ increases hematoma frequency at birth. Pharmacol Biochem Behav. 1993:45(4):959962.

11. Pastuszak A, Schick-Boschetto B, Zuber C -Pregnancy outcome following first. Trimester exposure to Fluoxetine (Prozac). JAMA. 1993;269:22462248.

12. Diav-Citrin O,Shechtman S, Weinbaum D, Wajnberg R, Avgil M, Di Gianantonio E, Clementi M, Weber-Schoendorfer C, Schaefer C, Ornoy A - Paroxetine and fluoxetine in pregnancy: A prospective, multicenter, controlled, observational study. Br J Clin Pharmacol. 2008;66(5):695-705. 